\title{
Perioperative Complications of Hysterectomy After a Previous Cesarean Section: A Systematic Review and Meta-Analysis
}

This article was published in the following Dove Press journal: Clinical Epidemiology

\author{
Siwanon Rattanakanokchai (iD) ' \\ Chumnan Kietpeerakool iD ${ }^{2}$ \\ Jatupol Srisomboon (iD ${ }^{3}$ \\ Nampet Jampathong (iD ${ }^{2}$ \\ Porjai Pattanittum ' \\ Pisake Lumbiganon ${ }^{2}$ \\ 'Department of Epidemiology and \\ Biostatistics, Faculty of Public Health, \\ Khon Kaen University, Khon Kaen 40002, \\ Thailand; ${ }^{2}$ Department of Obstetrics and \\ Gynecology, Faculty of Medicine, Khon \\ Kaen University, Khon Kaen 40002, \\ Thailand; ${ }^{3}$ Department of Obstetrics and \\ Gynecology, Faculty of Medicine, Chiang \\ Mai University, Chiang Mai, 50200, \\ Thailand
}

Background: With increasing rates of cesarean sections (CS), the number of hysterectomies performed among women with a previous CS is on the rise.

Objective: To provide the association between the odds of complications following a hysterectomy performed later in life and a previous CS.

Search strategy: A comprehensive search was performed using major electronic databases, ie, MEDLINE, Scopus, ISI Web of Science, from their inception to April 2019.

Selection criteria: Analytical studies, irrespective of language or publication status, were included.

Data collection and analysis: Outcomes were extracted in duplicate. The methodological quality of the included studies was independently evaluated by two review authors. A threelevel meta-analysis was applied for outcomes with dependent effect sizes.

Main results: Twenty-six studies were included involving 54,815 women. The odds of the following complications were increased in women with a previous CS: urinary tract injury (pooled unadjusted odds ratio $(\mathrm{OR})=3.15,95 \% \mathrm{CI}=2.01-4.94,15$ studies, 33,902 women, and pooled adjusted $\mathrm{OR}=2.21,95 \% \mathrm{CI}=1.46-3.34,3$ studies, 31,038 women), gastrointestinal tract injury (pooled unadjusted $\mathrm{OR}=1.73,95 \% \mathrm{CI}=1.19-2.53 ; 7$ studies, 30,050, and pooled adjusted $\mathrm{OR}=1.83,95 \% \mathrm{CI}=1.11-3.03,1$ study, 25,354 women), postoperative infections (pooled unadjusted $\mathrm{OR}=1.44,95 \% \mathrm{CI}=1.22-1.71,6$ studies, 37,832 women), wound complications (pooled unadjusted $\mathrm{OR}=2.24,95 \% \mathrm{CI}=1.94-2.57,9$ studies, 37,559 women), reoperation (pooled unadjusted $\mathrm{OR}=1.46,95 \% \mathrm{CI}=1.19-1.78,2$ studies, 9,899 women), and blood transfusion (pooled unadjusted $\mathrm{OR}=1.35,95 \% \mathrm{CI}=1.03-1.76,7$ studies, 13,430 women).

Conclusion: Previous CS increases risks of various complications following hysterectomy. This information reminds the gynecologists to be aware of the associations between previous $\mathrm{CS}$ and potential complications among women undergoing hysterectomy.

Prospero registration number: CRD42018085061.

Keywords: previous cesarean section, systematic review of hysterectomy, perioperative complications

\section{Introduction}

Cesarean section (CS) is the most common surgical procedure worldwide. When medically indicated, CS is a life-saving procedure in certain cases. ${ }^{1}$ There is no debate that the availability and adequate accessibility of safe CS are the foremost approaches for reducing adverse maternal and neonatal outcomes. ${ }^{1}$ There is, however, an alarming increase in CS rates worldwide. The rate varies widely among geographic regions. Latin America and the Caribbean carry the highest CS rate
Correspondence: Chumnan Kietpeerakool

Department of Obstetrics and

Gynecology, Faculty of Medicine, Khon

Kaen University, Khon Kaen 40002,

Thailand

Email kiet_ji@hotmail.com 
(40.5\%), followed by North America (32.3\%), Oceania (31.1\%), Europe (25\%), and Asia (19.2\%). The lowest CS rate is noted among African countries, with an average rate of $7.3 \% .^{2} \mathrm{CS}$ thus appears to be overused in some regions and underused in others. ${ }^{1}$

As for any major operation, CS increases short-term and long-term risks of adverse pregnancy outcomes. Shortterm risks of CS for mothers and infants include neonatal intensive care unit admission, postpartum hemorrhage, postpartum infection, prolonged hospital stay, and maternal admission to an intensive care unit. Long-term risks following CS are stillbirth, pre-term birth, placenta previa, morbidly adherent placenta, and uterine rupture. ${ }^{3}$

Hysterectomy is a common gynecological surgical procedure. With increasing rates of CS without any signs of slowing down, the number of hysterectomies performed among women with a previous history of $\mathrm{CS}$, therefore, is on the rise. Some previous studies noted higher rates of adjacent organ injury, postoperative infection, fistula formation, and blood transfusion among women undergoing hysterectomy who had a previous history of CS compared to those without a previous $\mathrm{CS}^{4,6}$ As there is a growing concern over the potential adverse effects of previous CS in women undergoing hysterectomy, it is imperative to address the strong evidence as to whether a previous CS leads to higher rates of complications following hysterectomy. Accordingly, this systematic review and meta-analysis was conducted with the goal of providing precise quantitative estimates of the magnitude of association between the risks of various surgical complications following hysterectomy later in life and a previous history of CS.

\section{Materials and Methods}

This systematic review was performed and reported according to the PRISMA statement. ${ }^{7}$ The PROSPERO ID for the protocol of this systematic review is CRD42018085061.

\section{Criteria for Considering Studies for This Review}

As a randomized controlled trial is not feasible due to the nature of this clinical question, analytical studies with available full-text, irrespective of language of publication, publication status, year of publication, or sample size were included. The population was adult women who underwent any kind of hysterectomy.

\section{Types of Outcome Measures}

Primary outcomes were urinary tract injury, gastrointestinal tract injury, and death. Secondary outcomes included postoperative febrile morbidity, postoperative infection, wound complications, fistula formation, reoperation, readmission, and blood component transfusion.

Dependent effect sizes of reported outcomes were anticipated; an example is where among the included studies, the effects of a previous CS are assessed on multiple variables for the same outcome. The occurrences of urinary tract injury, wound complications, and postoperative infection were compared between the groups on multiple related outcomes that resulted in a multiple dependent effect size to be synthesized.

\section{Search Strategy and Selection Criteria}

A comprehensive literature search was carried out using the major electronic databases including MEDLINE, PubMed, Scopus, ISI Web of Science, LILACS, Cochrane Central Register of Controlled Trials (CENTRAL), and CINAHL from their inception to April 2019. Reference lists of articles were checked for potential eligible studies. ClinicalTrials. gov and the WHO International Clinical Trials Registry Platform (www.who.int/ictrp) were searched for the ongoing study. Open Grey (www.opengrey.eu) was searched for grey literature. The titles of all relevant articles were identified on Google Scholar and then a further search was made related to these studies focusing on the first 50 records identified. ${ }^{8}$ The PubMed search strategy is presented in Table S1. This search strategy was adapted accordingly for other databases.

\section{Study Selection and Data Extraction}

Mendeley was used for merging and deduplicating search results, and then the results were transferred to Covidence software. Two review authors independently screened the titles and abstracts of studies retrieved by electronic searching. Studies where their titles and abstracts clearly did not meet the inclusion criteria were excluded. The full texts of potentially eligible studies were independently assessed by two review authors. Two review authors independently extracted data from the included studies using a data extraction form that was designed and pilot-tested. Any disagreements were resolved through discussion with the third review author.

\section{Risk of Bias Assessment}

The methodological quality of the included studies was independently evaluated by two review authors using the 
Newcastle-Ottawa Scale. The level of risk of bias included high, medium, and low criteria, as applied in the study of Viale et al. ${ }^{9}$ Briefly, studies that scored four stars for selection, two stars for comparability, and three stars for the outcome ascertainment were at a low risk of bias. Studies with two or three stars for selection, one for comparability, and two for outcome ascertainment were deemed to have a medium risk of bias. A study with a score of one for selection or outcome ascertainment, or zero for any of the three domains, was judged as having a high risk of bias.

\section{Data Analysis}

For each study, the log-odds ratio was calculated to estimate the association between history of previous cesarean section and outcome. For studies where no events were observed in one arm, a correction factor of 0.5 was added to all cells of the study results for estimating the effect sizes. ${ }^{10}$ Estimates pooled from the unadjusted odds ratios (OR) were reported separately to those from the ORs with an adjustment for the potential confounders.

For the outcomes with dependent effect sizes including urinary tract injury, wound complications, and postoperative infections, a three-level meta-analysis model was applied to avoid an overestimate of the pooled results. ${ }^{11,12}$ The three-level method accounts for three sources of variance: the sampling variance of the primary studies (level 1), the variance between effect sizes from the same study (level 2), as well as the variance between study (level 3). As a consequence, both within-study heterogeneity $\left(\sigma_{2}^{2}\right)$ and between-study heterogeneity $\left(\sigma_{3}^{2}\right)$ were analyzed and presented together with the percentage of distribution of total variance. A two-level meta-analysis was then applied for other outcomes considered as independent variables (i.e. blood transfusion, reoperation, and readmission). This model accounts for two sources of variance, including the sampling variance of the primary studies (level 1) and the variance between studies (level 2). In addition, the overall heterogeneity was examined by the Cochrane Q test with the cut-off for significance of 0.10.

The analyses were performed using $\mathrm{R}$ statistical software with the rma.mv function of the metafor package. The restricted maximum likelihood estimation method (REML) was followed for estimating the parameters in the model and executed without moderators. Then Z-distribution was used to calculate the confidence intervals (CI). Steps of a three-level meta-analysis were followed as has previously been done. ${ }^{13}$

\section{Sensitivity and Subgroup Analyses}

A funnel plot was created for the outcomes with more than ten included studies to assess potential publication bias. Subgroup analysis was carried out according to the types of surgical approach. Sensitivity analysis was conducted by repeating the analysis excluding studies judged to be at a high risk of bias.

\section{Results}

Of 76 studies that potentially met the review inclusion, four studies were excluded due to unavailable full texts (Table S2). Twenty-six studies were included in quantitative synthesis after reviewing the full texts (involving 54,815 women). ${ }^{4,6,14-37}$ All included studies were published in peer-reviewed journals (Figure 1).

The procedure performed in five included studies was vaginal hysterectomy. ${ }^{14,17,29,32,33}$ Ten of the remaining included studies assessed the odds of surgical complications following minimally invasive hysterectomy (laparoscopic-assisted vaginal hysterectomy, total laparoscopic hysterectomy, and roboticassisted hysterectomy) ${ }^{16,20-23,27,28,31,34,35}$ and 11 included studies assessed the odds of various types of hysterectomy including total abdominal hysterectomy and vaginal hysterectomy. ${ }^{4,6,15,18,19,24-26,30,36,37}$ Study designs of the included studies were cohort studies $(24)^{4,6,14-25,27-29,31-37}$ and case-control studies (two) ${ }^{26,30}$ (Tables S3 and S4).

Figure 2 shows the summary of the risk of biases stratified by the type of study design. Quality assessment among 24 cohort studies using the Newcastle-Ottawa Scale indicated that high risks for comparability and outcome assessment were, respectively, noted in $15^{14-18,21-25,27,28,33,34,36}$ and 12 studies. ${ }^{6,14,15,17,18,22,27,29,31,33,34,37}$ No cohort study was judged as having a high risk of selection bias. The two case-control studies ${ }^{26,30}$ included in this review were determined as having low-to-moderate risks of bias for all items.

The meta-analyses of the associations between previous $\mathrm{CS}$ and perioperative complications following hysterectomy are displayed in Figure 3. The odds of the following surgical complications after hysterectomy were significantly increased in women with a previous history of CS compared with those without CS: urinary tract injury (pooled unadjusted $\mathrm{OR}=3.15,95 \% \mathrm{CI}=2.01-4.94$, 15 studies; pooled adjusted $\mathrm{OR}=2.21,95 \% \mathrm{CI}=1.46-3.34$, 3 studies), gastrointestinal tract injury (pooled unadjusted $\mathrm{OR}=1.73,95 \% \mathrm{CI}=1.19-2.53,7$ studies; pooled adjusted $\mathrm{OR}=1.83,95 \% \quad \mathrm{CI}=1.11-3.03,1 \mathrm{study})$, postoperative infections (pooled unadjusted $\mathrm{OR}=1.44,95 \% \mathrm{CI}=1.22$ 


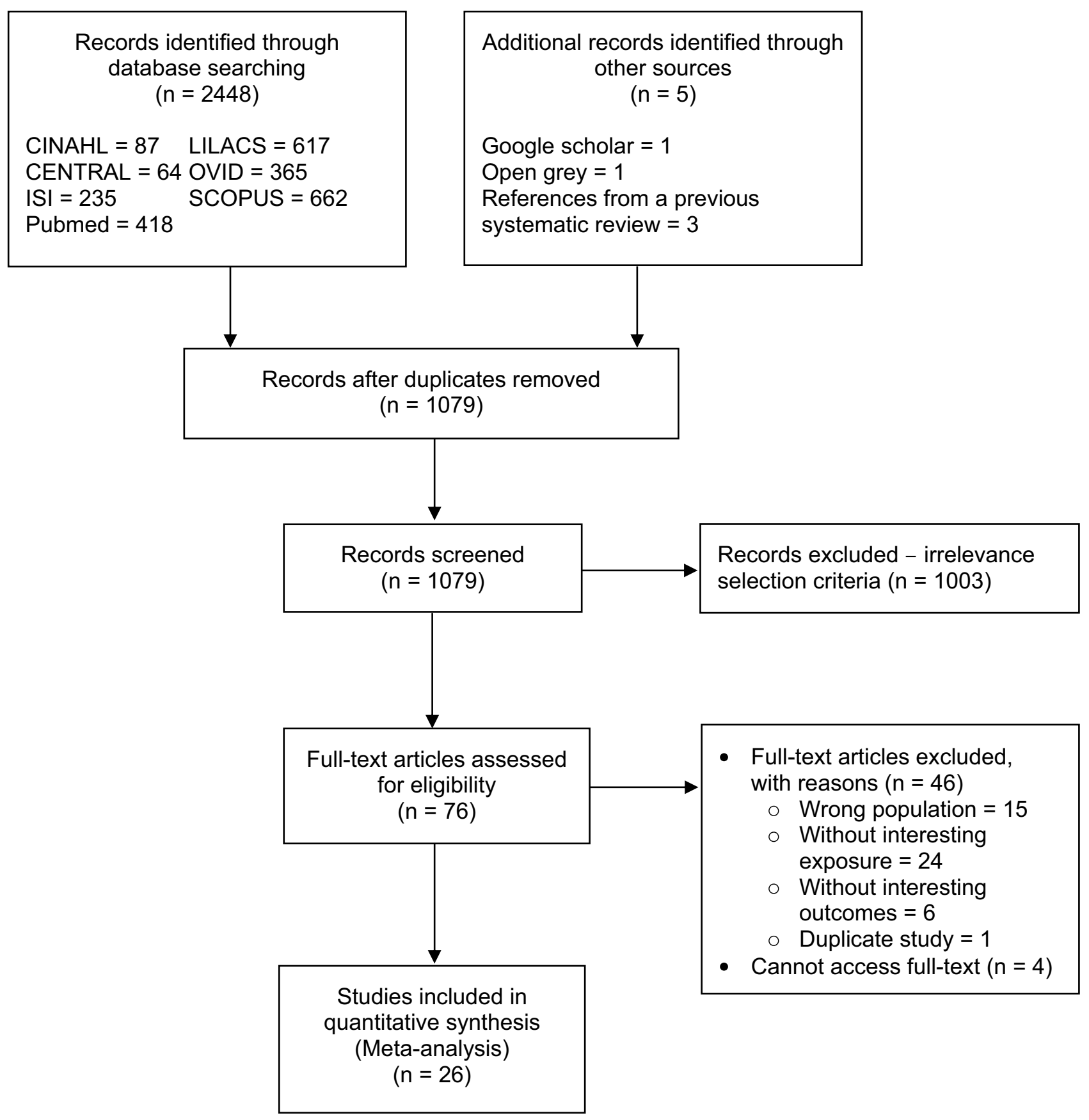

Figure I PRISMA flow diagram.

1.71, 6 studies), wound complications (pooled unadjusted $\mathrm{OR}=2.24,95 \% \mathrm{CI}=1.94-2.57,9$ studies), reoperation (pooled unadjusted $\mathrm{OR}=1.46,95 \% \mathrm{CI}=1.19-1.78,2$ studies), and blood component transfusion (pooled unadjusted $\mathrm{OR}=1.35 ; 95 \% \mathrm{CI}=1.03-1.76,7$ studies).

Of included studies with a reported unadjusted OR, previous CS significantly increased risk of bladder injury $(\mathrm{OR}=3.43,95 \% \mathrm{CI}=2.00-5.90,10$ studies $)$ and was marginally significantly associated with the risk of ureteric injury
$(\mathrm{OR}=2.85,95 \% \mathrm{CI}=1.00-8.15,6$ studies $)$. For those included studies with a reported adjusted OR (aOR), previous CS was significantly associated with an increased risk of bladder injury $(\mathrm{aOR}=2.58,95 \% \mathrm{CI}=1.63-4.10,3$ studies $)$, but was also marginally significant for the risk of ureteric injury ( $\mathrm{aOR}=1.44 ; 95 \% \mathrm{CI}=0.96-2.15,1$ study).

The higher risks of intraoperative injury to the urinary and gastrointestinal tracts among women with previous CS were consistently noted in the meta-analyses of either the 


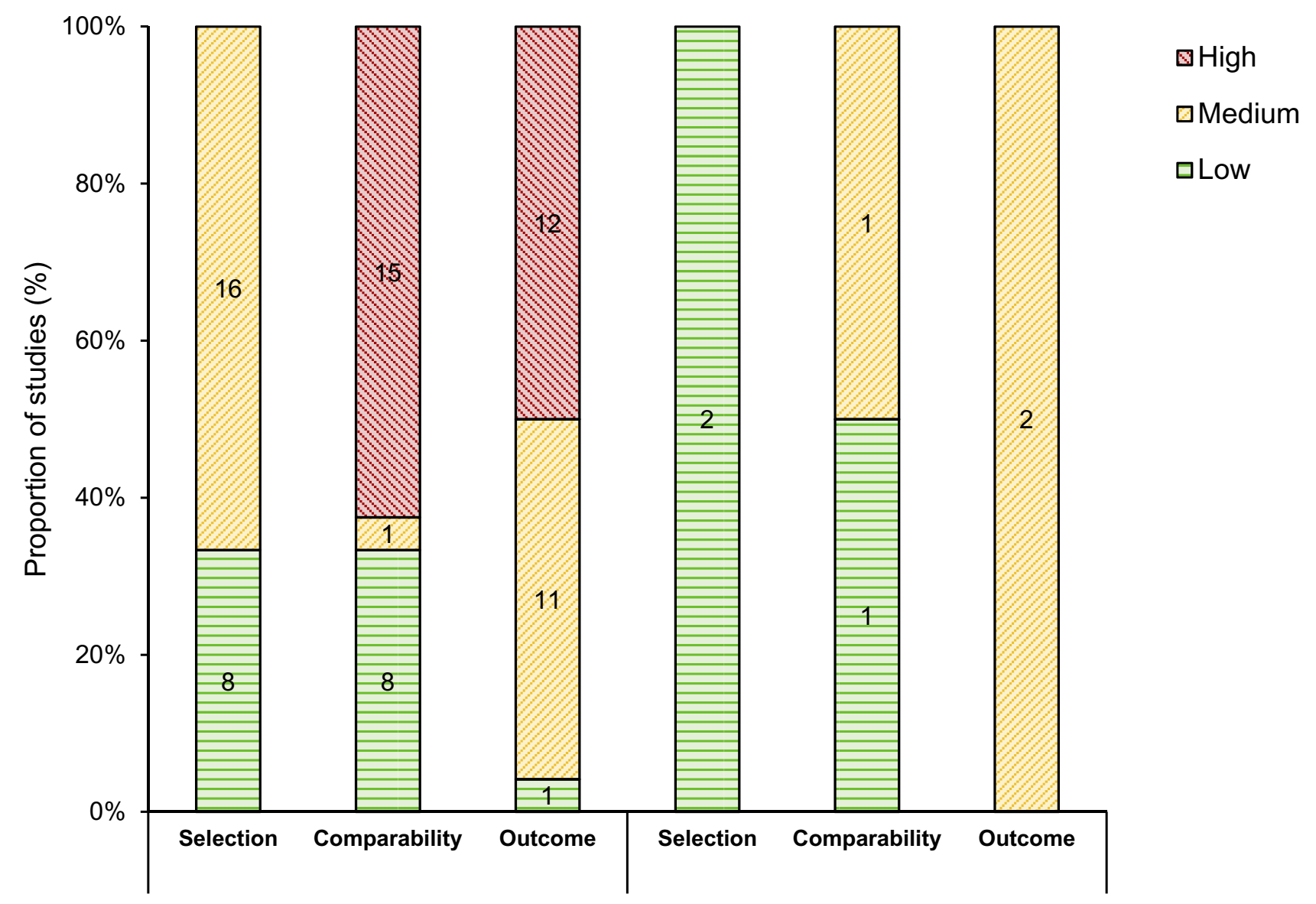

Figure 2 Risk of bias assessment using the Newcastle-Ottawa Scale for cohort (left; 24 studies) and case-control studies (right; two studies).

crude OR or adjusted OR (Figure 3). No differences were observed between the two comparison groups for death, fistula formation, postoperative febrile morbidity, and readmission. After an analysis was performed according to the study design, the risk of urinary tract injury during operation remained significantly elevated (Figure 4).

Subgroup analyses based on the types of surgical approach showed a significantly higher risk of urinary tract injury during minimally invasive hysterectomies. There was no significant impact of previous CS on the differences of perioperative complications among women undergoing vaginal hysterectomy (Table 1).

Sensitivity analyses by excluding studies with a high risk of bias showed no marked difference for the magnitude of association between the risks of perioperative complications following hysterectomy and a previous history of CS except a requirement of blood transfusion (Table 2). Publication bias could be responsible for the urinary tract injury, which showed a slightly asymmetrical funnel plot, thus indicating potential evidence of small study effects (Figure S1).

\section{Discussion}

\section{Main Findings}

This review provides evidence of the negative impacts of a previous history of CS on surgical complications following hysterectomy for gynecologic conditions performed in later life. Women with a previous CS carried higher odds of intraoperative injuries to gastrointestinal and urinary tracts, postoperative infections, wound complications, reoperation, and blood component transfusions. Sensitivity analyses by excluding studies with a high risk of bias showed no changes in the direction of these associations.

\section{Strengths and Limitations}

This review is the first comprehensive assessment of the associations between previous CS and surgical complications in subsequent hysterectomy performed later in life by metaanalyses. This review thereby was able to provide results with high precision owing to the large sample size. A three-level meta-analysis approach was also applied for some outcomes which involved jointly analyzing multiple and correlated variables to yield valid results. A considerably high number of 


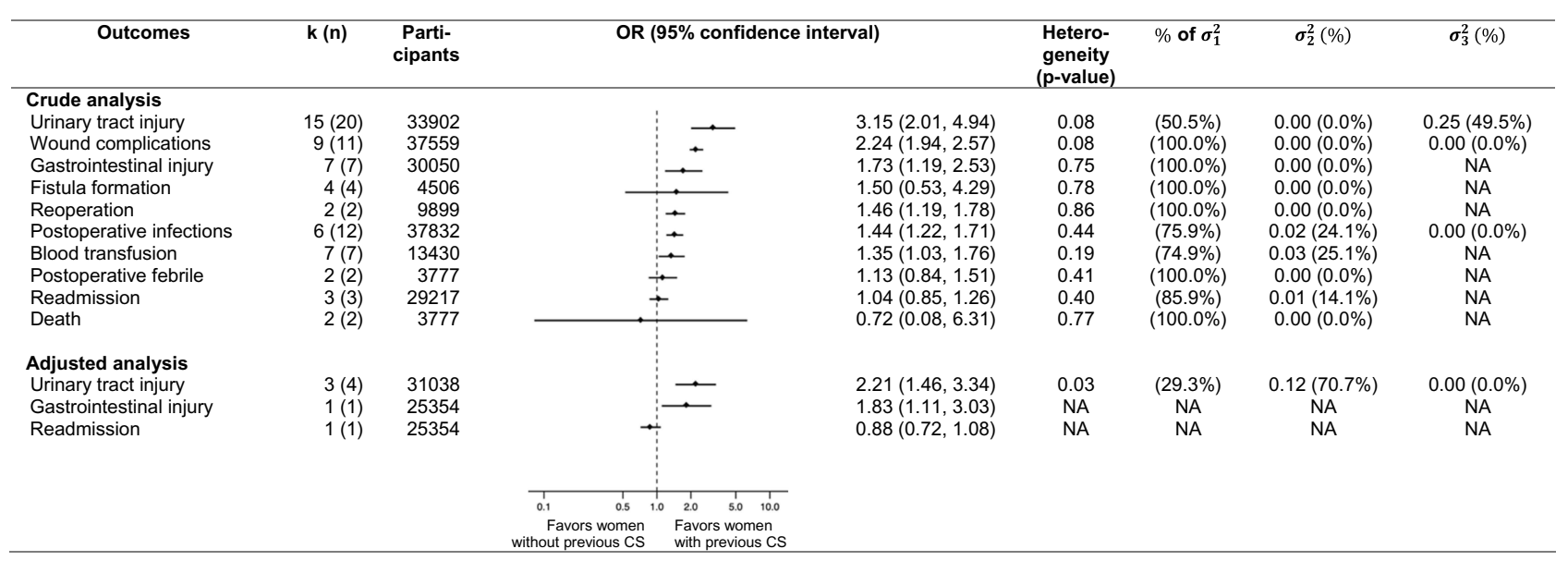

Figure 3 Meta-analysis of associations between previous cesarean delivery and perioperative complications in subsequent hysterectomy.

Abbreviations: $\mathrm{k}$, number of studies; $\mathrm{n}$, number reported outcomes; OR, odds ratio; previous CS, previous cesarean section; $\sigma_{1}^{2}$, sampling variance; $\sigma_{2}^{2}$, variance between reported outcomes from the same study; $\sigma_{3}^{2}$, variance between studies; NA, not applicable.

\begin{tabular}{|c|c|c|c|c|c|c|c|c|c|}
\hline Outcomes & $k(n)$ & $\begin{array}{l}\text { Parti- } \\
\text { cipants }\end{array}$ & OR ( & $5 \%$ confidence & erval) & $\begin{array}{l}\text { Hetero- } \\
\text { geneity } \\
\text { (p-value) }\end{array}$ & $\%$ of $\sigma_{1}^{2}$ & $\sigma_{2}^{2}(\%)$ & $\sigma_{3}^{2}(\%)$ \\
\hline \multicolumn{10}{|l|}{ Cohort study } \\
\hline Urinary tract injury & $14(19)$ & 33698 & & $\longrightarrow$ & $3.33(1.98,5.58)$ & 0.06 & $(45.8 \%)$ & $0.00(0.0 \%)$ & $0.33(54.2 \%)$ \\
\hline Wound complications & $9(11)$ & 37559 & & + & $2.24(1.94,2.57)$ & 0.08 & (100.0\%) & $0.00(0.0 \%)$ & $0.00(0.0 \%)$ \\
\hline Gastrointestinal injury & $7(7)$ & 30050 & & $\rightarrow$ & $1.73(1.19,2.53)$ & 0.75 & $(100.0 \%)$ & $0.00(0.0 \%)$ & NA \\
\hline Fistula formation & $4(4)$ & 4506 & & -. & $1.50(0.53,4.29)$ & 0.78 & $(100.0 \%)$ & $0.00(0.0 \%)$ & NA \\
\hline Reoperation & $2(2)$ & 9899 & & $\rightarrow$ & $1.46(1.19,1.78)$ & 0.86 & $(100.0 \%)$ & $0.00(0.0 \%)$ & NA \\
\hline Postoperative infections & $6(12)$ & 37832 & & $\leftarrow$ & $1.44(1.22,1.71)$ & 0.44 & $(75.9 \%)$ & $0.02(24.1 \%)$ & $0.00(0.0 \%)$ \\
\hline Postoperative febrile & $2(2)$ & 3777 & مهان & - & $1.13(0.84,1.51)$ & 0.41 & $(100.0 \%)$ & $0.00(0.0 \%)$ & NA \\
\hline Readmission & $3(3)$ & 29217 & $\vdots$ & & $1.04(0.85,1.26)$ & 0.40 & $(85.9 \%)$ & $0.01(14.1 \%)$ & NA \\
\hline Death & $2(2)$ & 3777 & & & $0.72(0.08,6.31)$ & 0.77 & $(100.0 \%)$ & $0.00(0.0 \%)$ & NA \\
\hline \multicolumn{10}{|l|}{ Adjusted analysis } \\
\hline Urinary tract injury & $2(3)$ & 30633 & & $\rightarrow$ & $1.89(1.36,2.63)$ & 0.13 & $(48.7 \%)$ & $0.04(51.3 \%)$ & $0.00(0.0 \%)$ \\
\hline Gastrointestinal injury & $1(1)$ & 25354 & & 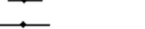 & $1.83(1.11,3.03)$ & NA & NA & NA & NA \\
\hline Readmission & $1(1)$ & 25354 & 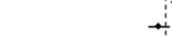 & & $0.88(0.72,1.08)$ & NA & NA & NA & NA \\
\hline \multicolumn{10}{|l|}{ Case-control study } \\
\hline Crude analysis & & & & & & & & & \\
\hline \multicolumn{10}{|l|}{ Adjusted analysis } \\
\hline \multirow[t]{2}{*}{ Urinary tract injury } & $1(1)$ & 405 & & $\longrightarrow$ & $2.90(1.68,5.00)$ & NA & NA & NA & NA \\
\hline & & & $\begin{array}{ccc}1 & 1 \\
0.1 & 0.5 & 1.0 \\
\text { Favors women } & \\
\text { without previous CS }\end{array}$ & $\begin{array}{ccc}1 & 1 & 1 \\
2.0 & 5.0 & 10.0 \\
\text { Favors women } \\
\text { with previous } \mathrm{CS}\end{array}$ & & & & & \\
\hline
\end{tabular}

Figure 4 Meta-analysis of associations between previous cesarean delivery and perioperative complications in subsequent hysterectomy according to the study design. Abbreviations: $\mathrm{k}$, number of studies; $\mathrm{n}$, number reported outcomes; OR, odds ratio; previous CS, previous cesarean section; $\sigma_{1}^{2}$, sampling variance; $\sigma_{2}^{2}$, variance between reported outcomes from the same study; $\sigma_{3}^{2}$, variance between studies; NA, not applicable.

included studies allowed this review to report various clinically relevant outcomes. In addition, the robustness of the review findings could be reaffirmed by sensitivity analyses.

This review has some limitations, relating mainly to the quality of the primary studies. It is anticipated that the more often the abdomen is entered, the more prevalent perioperative complications in the subsequent operations may be encountered. The impact of the numbers of previous $\mathrm{CS}$ on the magnitude of association, however, cannot be assessed due to limited available data. Potential evidence of publication bias in this review remains questionable and should be taken into an interpretation of findings. In addition, observational data are susceptible to selection bias and confounding that were not adjusted in many studies. Our findings, therefore, should be carefully interpreted in the context of the available information.

\section{Interpretation}

Previous CS has a negative effect on women's reproductive health. Long-term adverse pregnancy outcomes associated with a previous CS have been well acknowledged. The recent meta-analysis assessing long-term risks of previous CS on 
Table I Subgroup Analysis According to Routes of Operation

\begin{tabular}{|c|c|c|c|c|c|c|}
\hline \multirow[t]{3}{*}{ Outcomes } & \multicolumn{6}{|c|}{ Route of Operation } \\
\hline & \multicolumn{2}{|c|}{ Vaginal $(n=5)$} & \multicolumn{2}{|c|}{ Minimal Invasive $(n=10)$} & \multicolumn{2}{|c|}{$\operatorname{Mix}(n=I I)$} \\
\hline & $k(n)$ & OR (95\% CI) & $k(n)$ & OR (95\% CI) & $k(n)$ & OR (95\% CI) \\
\hline \multicolumn{7}{|l|}{ Crude Analysis } \\
\hline Urinary tract injury & $2(2)$ & $2.96(0.37-23.40)$ & $6(8)$ & $6.85(3.4 I-13.73)$ & $7(10)$ & $1.98(1.43-2.74)$ \\
\hline Wound complications & $I(I)$ & $0.20(0.02-1.60)$ & I (I) & $0.29(0.01-5.66)$ & 7 (9) & $2.27(\mathrm{I} .97-2.6 \mathrm{I})$ \\
\hline Gastrointestinal injury & I (I) & $9.56(0.59-154.47)$ & $2(2)$ & $1.64(0.26-10.50)$ & $4(4)$ & $1.68(1.14-2.48)$ \\
\hline Fistula formation & $2(2)$ & $0.87(0.18-4.17)$ & $0(0)$ & NA & $2(2)$ & $2.34(0.57-9.64)$ \\
\hline Reoperation & $0(0)$ & NA & $0(0)$ & NA & $2(2)$ & $1.46(1.19-1.78)$ \\
\hline Postoperative infections & $3(7)$ & $1.25(0.9|-| .72)$ & $0(0)$ & NA & $3(5)$ & $1.55(1.23-1.95)$ \\
\hline Blood transfusion & $3(3)$ & $0.96(0.30-3.06)$ & $I(I)$ & $0.93(0.42-2.05)$ & $3(3)$ & $1.46(1.01-2.10)$ \\
\hline Postoperative febrile & $I(I)$ & $0.91(0.50-1.64)$ & $0(0)$ & NA & $I(I)$ & $1.21(0.86-1.70)$ \\
\hline Readmission & $0(0)$ & NA & $0(0)$ & NA & $3(3)$ & $1.01(0.86-1.19)$ \\
\hline Death & I (I) & $0.50(0.02-12.42)$ & $0(0)$ & NA & $I(I)$ & $0.97(0.05-18.79)$ \\
\hline \multicolumn{7}{|l|}{ Adjusted Analysis } \\
\hline Urinary tract injury & $0(0)$ & NA & $0(0)$ & NA & $3(4)$ & $2.21(1.46-3.34)$ \\
\hline Gastrointestinal injury & $0(0)$ & NA & $0(0)$ & NA & $I(I)$ & $1.83(1.11-3.03)$ \\
\hline Readmission & $0(0)$ & NA & $0(0)$ & NA & $I(I)$ & $0.88(0.72-1.08)$ \\
\hline
\end{tabular}

Abbreviations: $n$, number of studies; $k$, number of studies for each outcome; (n), number of reported outcomes; OR, Odds ratio; Cl, confidence interval; NA, not applicable.

subsequent pregnancies indicated that pregnancy following previous CS was associated with higher risks of placenta previa $(\mathrm{OR}=1.74,95 \% \mathrm{CI}=1.62-1.87)$, morbidly adherent placenta $(\mathrm{OR}=2.95,95 \% \mathrm{CI}=1.32-6.60)$, placental abruption $(\mathrm{OR}=1.38,95 \% \mathrm{CI}=1.27-1.49)$, miscarriage $(\mathrm{OR}=1.17,95 \%$ $\mathrm{CI}=1.03-1.32)$ and stillbirth $(\mathrm{OR}=1.27,95 \% \mathrm{CI}=1.15-1.40) .{ }^{38}$

Postoperative adhesions play a central role for an increased risk of adjacent organ injury during subsequent operations. Adhesions can distort normal anatomy of organs that are in close surgical proximity to operation fields. Intraperitoneal adhesions form in $~ 25-45 \%$ after a first CS and they increase with the increasing number of CS. ${ }^{39}$ As would be anticipated, a previous CS is associated with a significantly higher risk of injury to urinary and gastrointestinal tracts during a repeat $\mathrm{CS}^{39,40}$ Intraperitoneal adhesion can prolong operative time in a subsequent surgery, which can result in higher perioperative morbidities. A recent cohort study assessing 6,507 repeated CS noted that women undergoing a repeated CS who experienced prolonged operative time carried higher risks of post-operative blood transfusion ( $4.4 \%$ vs $1.5 \%)$, prolonged hospitalization $(8.4 \%$ vs $4.0 \%)$, postoperative infection ( $2 \%$ vs $1 \%)$, and readmission $(1.8 \%$ vs $0.8 \%)$ when compared to those who did not repeat a $\mathrm{CS}^{41}$

In the attempt to depict a comprehensive view of long-term sequelae following CS, this meta-analysis was systematically conducted to assess the perioperative complications following hysterectomy performed later in life for gynecologic conditions among women with previous CS. This review did suggest some general trends in that a previous CS is associated with various adverse perioperative complications following hysterectomy. Thus, decisions on CS should take into account not only short-term adverse influences but also women's health in the long-term, including an increased risk of morbidities related to surgery performed later in life.

In this meta-analysis, urinary tract injury was the complication with the strongest association with previous CS. An increased risk of urinary tract injury among women having previous CS was consistently noted across the types of reported relative measures and designs of included studies. Even among women undergoing a minimally invasive approach, the risk of urinary tract injury remained significantly high. The increased risk of urinary tract injury following a minimally invasive approach among women with previous CS identified in this updated dataset aligns with a previous systematic review by $\mathrm{Xu}$ et al. ${ }^{5}$

The subgroup analysis showed that the magnitudes of association appeared to be related to the type of surgical approach. Although subgroup analyses indicated no significant association between previous CS and perioperative complications following vaginal hysterectomy, these findings, however, were obtained from a few small studies and 
Table 2 Sensitivity Analysis by Excluded High Risk of Bias Studies

\begin{tabular}{|c|c|c|c|c|}
\hline \multirow[t]{2}{*}{ Outcomes } & \multicolumn{2}{|c|}{ Original Analysis Results } & \multicolumn{2}{|c|}{ Sensitivity Analysis Results } \\
\hline & $k(n)$ & OR $(95 \% \mathrm{CI})$ & $k(n)$ & OR (95\% Cl) \\
\hline \multicolumn{5}{|l|}{ Crude Analysis } \\
\hline Urinary tract injury & $15(20)$ & $3.15(2.01-4.94)$ & $2(3)$ & $1.80(1.47-2.20)$ \\
\hline Wound complications & $9(11)$ & $2.24(1.94-2.57)$ & $I(I)$ & $2.21(1.90-2.57)$ \\
\hline Gastrointestinal injury & $7(7)$ & $1.73(1.19-2.53)$ & $I(I)$ & $1.90(1.21-2.98)$ \\
\hline Fistula formation & $4(4)$ & $1.50(0.53-4.29)$ & $0(0)$ & NA \\
\hline Reoperation & $2(2)$ & $1.46(1.19-1.78)$ & $0(0)$ & NA \\
\hline Postoperative infections & $6(12)$ & $1.44(|.22-| .7 \mid)$ & I (3) & $1.53(1.10-2.15)$ \\
\hline Blood transfusion & $7(7)$ & $1.35(1.03-1.76)$ & $I(I)$ & $0.14(0.01-2.35)$ \\
\hline Postoperative febrile & $2(2)$ & $1.13(0.84-1.5 \mathrm{I})$ & $0(0)$ & NA \\
\hline Death & $2(2)$ & $0.72(0.08-6.3 \mathrm{I})$ & $0(0)$ & NA \\
\hline Readmission & $3(3)$ & $1.01(0.85-1.26)$ & $\mathrm{I}(\mathrm{I})$ & $0.95(0.79-1.14)$ \\
\hline \multicolumn{5}{|l|}{ Adjusted Analysis } \\
\hline Urinary tract injury & $3(4)$ & $2.21(1.46-3.34)$ & $3(4)$ & $2.21(1.46-3.34)$ \\
\hline Gastrointestinal injury & I (I) & $1.83(1.11-3.03)$ & $I(I)$ & $1.83(1.11-3.03)$ \\
\hline Readmission & I (I) & $0.88(0.72-1.08)$ & $I(I)$ & $0.88(0.72-1.08)$ \\
\hline
\end{tabular}

Abbreviations: k, number of studies for each outcome; (n), number of reported outcomes; OR, Odds ratio; Cl, confidence interval; NA, not applicable.

thereby must be interpreted with caution. A future largescale study is required to confirm this finding.

CS not only increases the odds of short-term adverse events to pregnant women, the fetus, or both, but also the odds of adverse events following hysterectomy performed later in life. Although, CS may associate with lower risks for stress urinary incontinence, overactive bladder, and pelvic organ prolapse compared with spontaneous vaginal delivery, ${ }^{42}$ these benefits should be weighed against the risk of potential complications.

\section{Conclusion}

A clinically relevant view of this meta-analysis of observational studies indicates a higher risk of various perioperative complications following hysterectomy for gynecological conditions among women with at least one previous CS, particularly the risks for urinary tract injury. This information is, therefore, helpful to remind the gynecologists to be aware of the potential complications following hysterectomy among women with a prior history of CS.

\section{Acknowledgment}

We would like to acknowledge Emeritus Professor James A. Will, University of Wisconsin-Madison, for editing the manuscript via the publication clinic KKU, Thailand.

\section{Author Contributions}

This study was conceptualized by CK, JS, and PL. SR and $\mathrm{CK}$ did the database search, title and abstract screening, full-text screening, and data extraction. All authors contributed to data analysis, drafting or revising the article, gave final approval of the version to be published, and agree to be accountable for all aspects of the work.

\section{Disclosure}

The authors report no funding and no conflicts of interest in this work.

\section{References}

1. Betrán AP, Temmerman M, Kingdon $\mathrm{C}$, et al. Interventions to reduce unnecessary caesarean sections in healthy women and babies. Lancet. 2018;392(10155):1358-1368. doi:10.1016/S0140-6736(18)31927-5

2. Betran AP, Ye J, Moller AB, Zhang J, Gulmezoglu AM, Torloni MR. The increasing trend in caesarean section rates: global, regional and national estimates: 1990-2014. PLoS One. 2016;11(2):e0148343. doi:10.1371/journal.pone.0148343PONE-D-15-47913[pii]

3. Sandall J, Tribe RM, Avery L, et al. Short-term and long-term effects of caesarean section on the health of women and children. Lancet. 2018;392(10155):1349-1357. doi:10.1016/S0140-6736(18) 31930-5

4. Brummer THI, Jalkanen J, Fraser J, et al. FINHYST, a prospective study of 5279 hysterectomies: complications and their risk factors. Hum Reprod. 2011;26(7):1741-1751. doi:10.10 93/humrep/der116

5. Xu Y, Wang Q, Wang F. Previous cesarean section and risk of urinary tract injury during laparoscopic hysterectomy: a meta-analysis. Int Urogynecol J. 2015;26(9):1269-1275. doi:10.1007/s00192-0152653-5 
6. Lindquist SAI, Shah N, Overgaard C, et al. Association of previous cesarean delivery with surgical complications after a hysterectomy later in life. JAMA Surg. 2017;152(12):1148-1155. doi:10.1001/ jamasurg.2017.2825

7. Liberati A, Altman DG, Tetzlaff J, et al. The PRISMA statement for reporting systematic reviews and meta-analyses of studies that evaluate health care interventions: explanation and elaboration. J Clin Epidemiol. 2009;62(10):e1-e34. doi:10.1016/j.jclinepi.2009.06.006

8. Haddaway NR, Collins AM, Coughlin D, Kirk S. The role of google scholar in evidence reviews and its applicability to grey literature searching. Wray KB, ed. PLoS One. 2015;10(9):e0138237. doi:10.1371/journal.pone.0138237

9. Viale L, Allotey J, Cheong-See F, et al. Epilepsy in pregnancy and reproductive outcomes: a systematic review and meta-analysis. Lancet. 2015;386(10006):1845-1852. doi:10.1016/S0140-6736(15) 00045-8

10. Deeks JJ, Higgins JPT, Altman DG, editors. Chapter 10: analysing data and undertaking meta-analyses. In: Higgins JPT, Thomason J, Chandler J, et al., editors. Cochrane Handbook for Systematic Reviews of Interventions Version 6.0 (Updated July 2019). Cochrane; 2019. Available from: www.training.cochrane.org/hand book.Accessed December 12, 2019.

11. Moeyaert M, Ugille M, Natasha Beretvas S, Ferron J, Bunuan R, Van den Noortgate W. Methods for dealing with multiple outcomes in meta-analysis: a comparison between averaging effect sizes, robust variance estimation and multilevel meta-analysis. Int J Soc Res Methodol. 2017;20(6):559-572. doi:10.1080/13645579.2016.125 2189

12. Van den Noortgate W, López-López JA, Marín-Martínez F, SánchezMeca J. Three-level meta-analysis of dependent effect sizes. Behav Res Methods. 2013;45(2):576-594. doi:10.3758/s13428-012-0261-6

13. Assink M, Wibbelink CJM. Fitting three-level meta-analytic models in R: a step-by-step tutorial. Quant Methods Psychol. 2016;12 (3):154-174. doi:10.20982/tqmp.12.3.p154

14. Boukerrou M, Lambaudie E, Collinet P, Crépin G, Cosson M. L'antécédent de césarienne est un facteur de risque opératoire de l'hystérectomie vaginale [Previous cesarean section is an opeative risk factor in vaginal hysterectomy]. Gynecol Obstet Fertil. 2004;32 (6):490-495. doi:10.1016/j.gyobfe.2004.04.002

15. Celle C, Pomés C, Durruty G, Zamboni M, Cuello M. Total laparoscopic hysterectomy with previous cesarean section using a standardized technique: experience of Pontificia Universidad Catolica de Chile. Gynecol Surg. 2015;12(3):149-155. doi:10.1007/ s10397-015-0896-2

16. Chang WC, Torng PL, Huang SC, et al. Laparoscopic-assisted vaginal hysterectomy with uterine artery ligation through retrograde umbilical ligament tracking. J Minim Invasive Gynecol. 2005;12 (4):336-342. doi:10.1016/j.jmig.2005.05.006

17. Coulam CB, Pratt JH. Vaginal hysterectomy: is previous pelvic operation a contraindication? Am J Obstet Gynecol. 1973;116(2):252-260. doi:10.1016/0002-9378(73)91060-0

18. Duong TH, Patterson TM. Lower urinary tract injuries during hysterectomy in women with a history of two or more cesarean deliveries: a secondary analysis. Int Urogynecol J. 2014;25(8):1037-1040. doi:10.1007/s00192-013-2324-3

19. Hesselman S, Högberg U, Jonsson M. Effect of remote cesarean delivery on complications during hysterectomy: a cohort study. Am J Obstet Gynecol. 2017;217(5):564.e1-564.e8. doi:10.1016/j.ajog.2017.07.021

20. Hobson DTG, Imudia AN, Al-Safi ZA, Shade G, Diamond MP, Awonuga AO. Prior cesarean delivery and risk of conversion to laparotomy during laparoscopic hysterectomy. J Gynecol Surg. 2013;29(6):275-280. doi:10.1089/gyn.2013.0018

21. İnan AH, Budak A, Beyan E, Kanmaz AG. The incidence, causes, and management of lower urinary tract injury during total laparoscopic hysterectomy. J Gynecol Obstet Hum Reprod. 2019;48 (1):45-49. doi:10.1016/j.jogoh.2018.10.009
22. Jo EJ, Kim T-J, Lee -Y-Y, et al. Laparoendoscopic single-site surgery with hysterectomy in patients with prior cesarean section: comparison of surgical outcomes with bladder dissection techniques. J Minim Invasive Gynecol. 2013;20(2):160-165. doi:10.1016/j.jmig.2012.09.013

23. Koroglu N, Cetin BA, Turan G, Yıldırım GY, Akca A, Gedikbasi A. Characteristics of total laparoscopic hysterectomy among women with or without previous cesarean section: retrospective analysis. Sao Paulo Med J. 2018;136(5):385-389. doi:10.1590/1516-3180.2018.0197030718

24. Lee MS, Venkatesh KK, Growdon WB, Ecker JL, York-Best CM. Predictors of 30-day readmission following hysterectomy for benign and malignant indications at a tertiary care academic medical center. Am J Obstet Gynecol. 2016;214(5):607e1-607e12. doi:10.1016/j. ajog.2015.11.037

25. Lim S, Lee S, Choi J, Chon S, Lee K, Shin J. Safety of total laparoscopic hysterectomy in patients with prior cesarean section. J Obstet Gynaecol Res. 2017;43(1):196-201. doi:10.1111/jog.13191

26. Mamik MM, Antosh D, White DE, et al. Risk factors for lower urinary tract injury at the time of hysterectomy for benign reasons. Int Urogynecol J. 2014;25(8):1031-1036. doi:10.1007/s00192-0132308-3

27. Morgan-Ortiz F, Soto-Pineda JM, López-Zepeda MA, Peraza-Garay FDJ. Effect of body mass index on clinical outcomes of patients undergoing total laparoscopic hysterectomy. Int J Gynecol Obstet. 2013;120(1):61-64. doi:10.1016/j.ijgo.2012.08.012

28. Pillet M-CL, Leonard F, Chopin N, et al. Incidence and risk factors of bladder injuries during laparoscopic hysterectomy indicated for benign uterine pathologies: a 14.5 years experience in a continuous series of 1501 procedures. Hum Reprod. 2009;24(4):842-849. doi:10.1093/humrep/den467

29. Poindexter YM, Sangi-Haghpeykar H, Poindexter AN 3rd, et al. Previous cesarean section. A contraindication to vaginal hysterectomy? J Reprod Med. 2001;46(9):840-844.

30. Rooney CM, Crawford AT, Vassallo BJ, Kleeman SD, Karram MM. Is previous cesarean section a risk for incidental cystotomy at the time of hysterectomy? A case-controlled study. Am J Obs Gynecol. 2005;193(6):2041-2044. doi:10.1016/j.ajog.2005.07.090

31. Saito A, Hirata T, Koga K, et al. Preoperative assessment of factors associated with difficulty in performing total laparoscopic hysterectomy. J Obstet Gynaecol Res. 2017;43(2):320-329. doi:10.1111/jog.13198

32. Schmitt JJ, Occhino JA, Weaver AL, McGree ME, Gebhart JB. Outcomes of vaginal hysterectomy with and without perceived contraindications to vaginal surgery. Female Pelvic Med Reconstr Surg. 2019;25(1):41-48. doi:10.1097/SPV.0000000000000469

33. Sheth SS, Malpani AN. Vaginal hysterectomy following previous cesarean section. Int J Gynecol Obstet. 1995;50(2):165-169. doi:10.1016/0020-7292(95)02434-E

34. Sinha R, Sundaram M, Nikam YA, Hegde A, Mahajan C. Total laparoscopic hysterectomy with earlier uterine artery ligation. J Minim Invasive Gynecol. 2008;15(3):355-359. doi:10.1016/j. jmig.2008.01.012

35. Song T, Kim T-J, Kang H, et al. Factors associated with complications and conversion to laparotomy in women undergoing laparoscopically assisted vaginal hysterectomy. Acta Obstet Gynecol Scand. 2012;91(5):620-624. doi:10.1111/j.1600-0412.2012.01376.x

36. Unger JB, Meeks GR. Vaginal hysterectomy in women with history of previous cesarean delivery. Am J Obs Gynecol. 1998;179(6 Pt 1):1473-1478. doi:10.1016/S0002-9378(98)70011-0

37. Wang L, Merkur H, Hardas G, Soo S, Lujic S. Laparoscopic hysterectomy in the presence of previous caesarean section: a review of one hundred forty-one cases in the Sydney west advanced pelvic surgery unit. J Minim Invasive Gynecol. 2010;17(2):186-191. doi:10.1016/j. jmig.2009.11.007

38. Keag OE, Norman JE, Stock SJ. Long-term risks and benefits associated with cesarean delivery for mother, baby, and subsequent pregnancies: systematic review and meta-analysis. Myers JE, ed. PLoS Med. 2018;15(1):e1002494. doi:10.1371/journal.pmed.1002494 
39. Awonuga AO, Fletcher NM, Saed GM, Diamond MP. Postoperative adhesion development following cesarean and open intra-abdominal gynecological operations. Reprod Sci. 2011;18(12):1166-1185. doi: $10.1177 / 1933719111414206$

40. Phipps MG, Watabe B, Clemons JL, Weitzen S, Myers DL. Risk factors for bladder injury during cesarean delivery. Obstet Gynecol. 2005;105(1):156-160. doi:10.1097/01.AOG.0000149150.93552.78
41. Rottenstreich M, Sela HY, Shen O, Michaelson-Cohen R, Samueloff A, Reichman O. Prolonged operative time of repeat cesarean is a risk marker for post-operative maternal complications. BMC Pregnancy Childbirth. 2018;18(1):477. doi:10.1186/s12884-018-2111-8

42. Blomquist JL, Muñoz A, Carroll M, Handa VL. Association of delivery mode with pelvic floor disorders after childbirth. JAMA. 2018;320(23):2438. doi:10.1001/jama.2018.18315

\section{Publish your work in this journal}

Clinical Epidemiology is an international, peer-reviewed, open access, online journal focusing on disease and drug epidemiology, identification of risk factors and screening procedures to develop optimal preventative initiatives and programs. Specific topics include: diagnosis, prognosis, treatment, screening, prevention, risk factor modification,

Submit your manuscript here: https://www.dovepress.com/clinical-epidemiology-journal systematic reviews, risk \& safety of medical interventions, epidemiology \& biostatistical methods, and evaluation of guidelines, translational medicine, health policies \& economic evaluations. The manuscript management system is completely online and includes a very quick and fair peer-review system, which is all easy to use. 